\title{
Vitamin D status in a multi-ethnic population of northern Norway: the SAMINOR 2 Clinical Survey
}

\author{
Natalia Petrenya ${ }^{1, *}$, Christel Lamberg-Allardt ${ }^{2}$, Marita Melhus ${ }^{3}$, Ann Ragnhild Broderstad ${ }^{3}$ \\ and Magritt Brustad ${ }^{1}$ \\ 'Department of Community Medicine, Faculty of Health Sciences, UiT The Arctic University of Norway, Postboks \\ 6050 Langnes 9037, Tromsø, Norway: ${ }^{2}$ Calcium Research Unit, Department of Food and Nutrition Sciences, \\ University of Helsinki, Helsinki, Finland: ${ }^{3}$ Centre for Sami Health Research, Department of Community Medicine, UiT \\ The Arctic University of Norway, Tromsø, Norway
}

Submitted 8 February 2018: Final revision received 17 0ctober 2018: Accepted 5 December 2018: First published online 15 February 2019

\begin{abstract}
Objective: To investigate serum 25-hydroxyvitamin D (S-25(OH)D) concentration in a multi-ethnic population of northern Norway and determine predictors of S-25(OH)D, including Sami ethnicity.

Design: Cross-sectional data from the second survey of the Population-based Study on Health and Living Conditions in Regions with Sami and Norwegian Populations (the SAMINOR 2 Clinical Survey, 2012-2014). S-25(OH)D was measured by the IDS-iSYS 25-Hydroxy Vitamin $\mathrm{D}^{\mathrm{s}}$ assay. Daily dietary intake was assessed using an FFQ. BMI was calculated using weight and height measurements.

Setting: Ten municipalities of northern Norway (latitude $68^{\circ}-70^{\circ} \mathrm{N}$ ).

Participants: Males ( $n$ 2041) and females ( $n$ 2424) aged $40-69$ years.

Results: Mean S-25(OH)D in the study sample was $64.0 \mathrm{nmol} / \mathrm{l}$ and median vitamin $\mathrm{D}$ intake was $10.3 \mu \mathrm{g} / \mathrm{d}$. The prevalence of S-25(OH)D $<30 \mathrm{nmol} / 1$ was $1.9 \%$ and $<50 \mathrm{nmol} / 1$ was $24.7 \%$. In sex-specific multivariable linear regression models, older age, blood sample collection in September-October, solarium use, sunbathing holiday, higher alcohol intake (in females), use of cod-liver oil/fish oil supplements, use of vitamin/mineral supplements and higher intakes of vitamin D were significantly associated with higher S-25(OH)D, whereas being a current smoker and obesity were associated with lower S-25(OH)D. These factors explained $21-23 \%$ of the variation in $\mathrm{S}-25(\mathrm{OH}) \mathrm{D}$.

Conclusions: There were many modifiable risk factors related to S-25(OH)D, however no clear ethnic differences were found. Even in winter, the low prevalence of vitamin D deficiency found among participants with non-Sami, multi-ethnic Sami and Sami self-perceived ethnicity was likely due to adequate vitamin D intake.
\end{abstract}

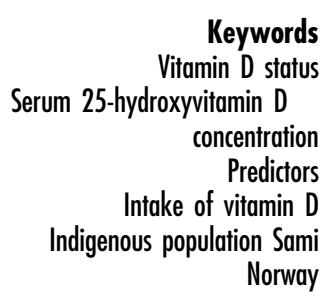

Keywords

yvitamin D

Predictors

Intake of vitamin D

Norway
Vitamin D regulates Ca and P homeostasis and is essential for the health of bones, teeth and muscles ${ }^{(1)}$. People obtain vitamin D through UVB-activated skin production and through dietary intake ${ }^{(2)}$; however, natural dietary sources of vitamin D are limited. In the Norwegian diet, the most valuable sources include cod-liver oil supplements, oily fish, fortified butter and margarine, in addition to traditional foods like cod liver and hard roe ${ }^{(3-5)}$.

Currently, 25-hydroxyvitamin D (25(OH)D) concentration is the best indicator of vitamin $\mathrm{D}$ status. There is an ongoing debate on the optimal concentration of $25(\mathrm{OH}) \mathrm{D}^{(6)}$. In terms of bone health, the US Institute of Medicine has stated that, for $97.5 \%$ of the world's population, a $25(\mathrm{OH}) \mathrm{D}$ concentration of $50 \mathrm{nmol} / 1$ would be equivalent to vitamin D sufficiency; a concentration of $<30 \mathrm{nmol} / \mathrm{l}$ is attributed to a risk of vitamin D deficiency ${ }^{(7)}$.

Hypovitaminosis D is prevalent in the European population. A recent publication on vitamin $\mathrm{D}$ deficiency in Europe found that 40.4 and $13.0 \%$ of tested individuals had $25(\mathrm{OH}) \mathrm{D}$ concentration $<50 \mathrm{nmol} / \mathrm{l}$ and $<30 \mathrm{nmol} / \mathrm{l}$, respectively ${ }^{(8)}$.

Several population-based studies have evaluated the distribution of and factors related to $25(\mathrm{OH}) \mathrm{D}$ concentration in the Norwegian population ${ }^{(4,9-14)}$. The Vitamin D Standardization Program (VDSP) ${ }^{(15,16)}$ created a protocol that can be used for retrospective standardization of 
$25(\mathrm{OH}) \mathrm{D}$ data to make them comparable with other standardized studies. It was applied to two nationally representative surveys of adults aged 30 years and 45 years or older in Norway. The results showed a lower prevalence of $25(\mathrm{OH}) \mathrm{D}<50 \mathrm{nmol} / \mathrm{l}$ and $<30 \mathrm{nmol} / \mathrm{l}$ compared with other European studies: 15.0 and $1.3 \%$, respectively, in a cohort from Oslo (the HUBRO Study, Norwegians with Pakistan ethnicity were excluded) ${ }^{(17)}$; and 18.6 and $0.9 \%$, respectively, in a cohort from Troms $\varnothing$ (the Troms $\varnothing$ Study-6th Survey $)^{(8)}$. Seasonal fluctuation in $25(\mathrm{OH}) \mathrm{D}$ concentration has been well documented in European populations ${ }^{(8)}$, and studies from Norway have also reported drops in $25(\mathrm{OH}) \mathrm{D}$ concentration during winter $^{(4,11,13)}$. However, because vitamin D supplements like cod-liver oil are widely used in Norway ${ }^{(18)}$, the amplitude of seasonal fluctuations in $25(\mathrm{OH}) \mathrm{D}$ in northern Norway is smaller than in central European countries ${ }^{(19)}$.

Population groups that may be at high risk of vitamin D deficiency in Norway include elderly nursing home residents, particularly those who do not use vitamin D supplements $^{(20)}$, adolescents ${ }^{(9)}$ and certain non-Western immigrant groups ${ }^{(12,21,22)}$. In fact, in the HUBRO Study, $65 \%$ of Norwegians with Pakistan ethnicity had a 25(OH)D concentration of $<30 \mathrm{nmol} / \mathrm{l}$ and $92 \%$ had a concentration of $<50 \mathrm{nmol} / \mathrm{l}^{(17)}$.

In the Norwegian population, predictors of $25(\mathrm{OH}) \mathrm{D}$ concentration include daily dietary intake of vitamin $\mathrm{D}^{(4)}$, intake of vitamin D supplements ${ }^{(11,13)}$ and season $^{(4,11,13,23)}$. In addition, 25(OH)D concentration has been found to be positively associated with increased physical activity ${ }^{(11,13)}$, frequent alcohol consumption ${ }^{(13)}$ and estimated daily hours of exposure to UVB radiation ${ }^{(4)}$. On the other hand, 25(OH)D concentration has been negatively associated with current smoking ${ }^{(13)}$, high $\mathrm{BMI}^{(11,13)}$ and not having a holiday at southern latitudes during the previous summer ${ }^{(4)}$.

Vitamin D status is of special concern in northern geographical areas. In the most northern part of Norway $\left(69-71^{\circ} \mathrm{N}\right)$, UVB-activated skin production of vitamin $\mathrm{D}$ is limited or absent for a considerable part of the year (October-March) ${ }^{(24)}$. Fish liver and fresh fish-liver oil, which have some of the highest vitamin $\mathrm{D}$ content, are traditionally consumed in northern Norway, but mainly in coastal communities ${ }^{(5)}$. Cod (Gadus mothua L.) liver is consumed during the winter months (January-March/ April) and saithe (Pollachius virens) liver is consumed from late summer until autumn (July-September/October). Reduction of consumption of traditional foods has been shown to be associated with insufficient nutrient intakes and a decrease in circulating 25(OH)D concentration among certain Indigenous populations in the $\operatorname{Arctic}^{(25,26)}$

The population of northern Norway is multi-ethnic and comprises the Indigenous ethnic group Sami. Nutritional rickets already received attention in this population in 1928-1929, when a high prevalence of this condition was reported among children in those Sami communities in Finnmark, where there is limited access to seafood ${ }^{(27)}$. A dietary pattern analysis based on the first survey of the Population-based Study on Health and Living Conditions in Regions with Sami and Norwegian Populations (the SAMINOR 1 Survey, 2003-2004) showed that dietary patterns differed by geographical region and ethnicity ${ }^{(28)}$. A dietary pattern that included a high intake of reindeer meat was dominant in inland areas and among participants with a strong Sami affiliation, while higher fish consumption was common in coastal areas. To the best of our knowledge, no large-scale mixed-gender studies on vitamin D status that cover both inland and coastal geographical areas of northern Norway have been conducted. Furthermore, no studies have explored this issue according to Sami ethnicity. The main goal of the present study was to determine serum $25(\mathrm{OH}) \mathrm{D}(\mathrm{S}-25(\mathrm{OH}) \mathrm{D})$ concentration in a multi-ethnic population of northern Norway and to investigate predictors of vitamin D status, including Sami ethnicity.

\section{Methods}

\section{Study design and population}

The second survey of the Population-based Study on Health and Living Conditions in Regions with Sami and Norwegian Populations (the SAMINOR 2 Clinical Survey) was conducted by the Centre for Sami Health Research, UiT The Arctic University of Norway. Data collection was carried out in ten municipalities of northern Norway (Skånland, Evenes, Kåfjord, Storfjord, Karasjok, Kautokeino, Porsanger, Tana, Nesseby and Lyngen; latitude 68$70^{\circ} \mathrm{N}$ ) in 2012-2014 (Fig. 1). These municipalities were selected based on a large proportion of Sami inhabitants. All inhabitants aged 40-79 years and residing in these municipalities were invited to participate in the study by personal letter. Data were collected through an eight-page self-administered questionnaire (see www.saminor.no for an English translation of the questionnaire), a short clinical examination, and blood sample collection and analysis. The questionnaire was prepared in Norwegian and then translated into the Northern Sami language. The questionnaire distributed to participants aged 40-69 years ( $n$ 10 399) contained a four-page FFQ. In this age group, 4876 attended the survey (participation rate $47 \%$ ). The response was higher among females (54\%) than males (40\%).

\section{Determination of serum 25-hydroxyvitamin $D$ concentration}

Non-fasting blood samples were collected during the clinical examination. Sampling in Skånland and Evenes was performed in September-October 2012, in Karasjok in January-February 2013, in Kautokeino in February-March 


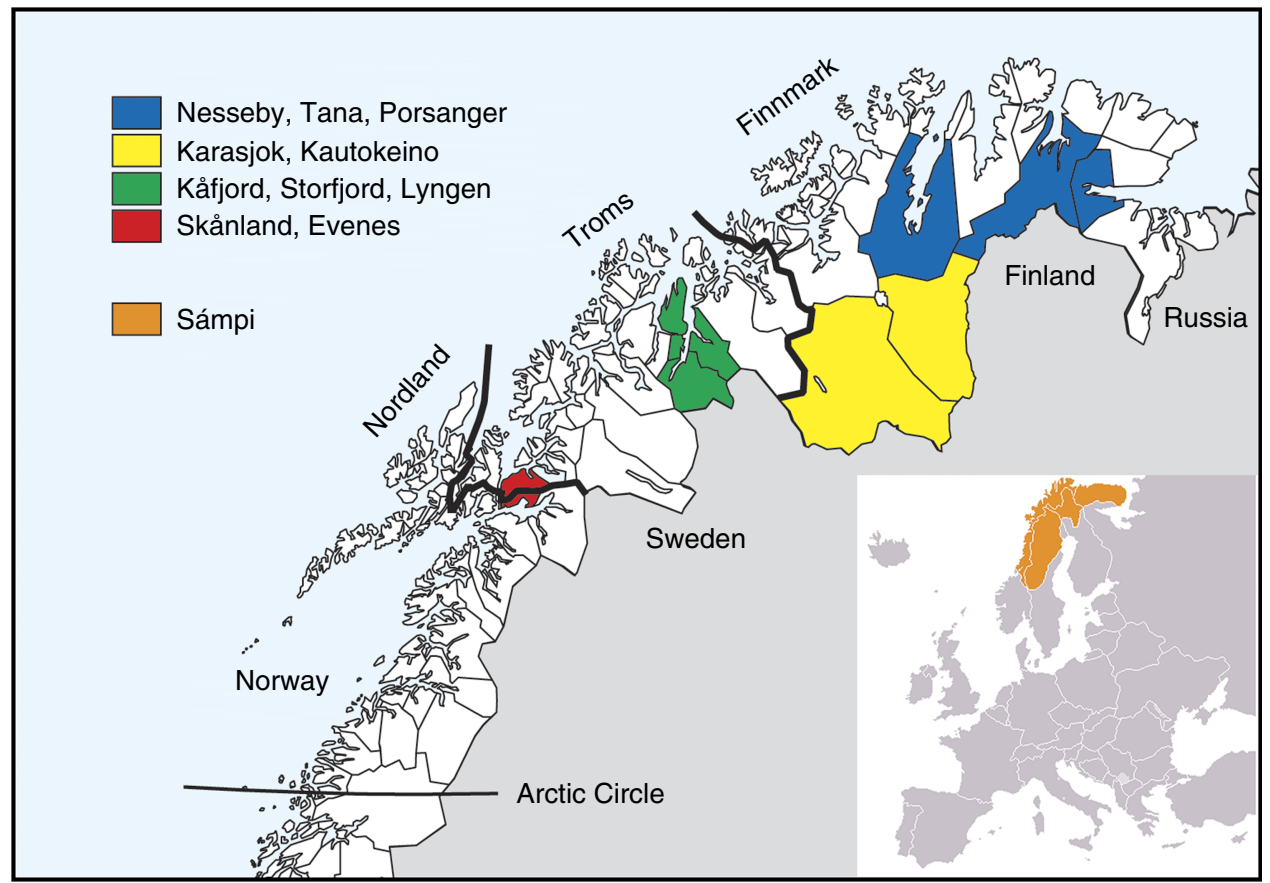

Fig. 1 Map of study sites

2013, in Porsanger in April-May 2013, in Kåfjord in September-October 2013, in Storfjord in OctoberNovember 2013, in Tana and Nesseby in February-April 2014, and in Lyngen in May-June 2014.

No sampling was performed in December, July or August. Resultant serum samples were stored at $-70^{\circ} \mathrm{C}$ and used to assess S-25(OH)D concentration by the IDS-iSYS 25-Hydroxy Vitamin $D^{\mathrm{s}}$ assay on the IDS-iSYS analyser (IDS Ltd, Boldon, UK) at the Department of Food and Environmental Sciences, University of Helsinki ( $n$ 4832). The assay is validated and certified by the VDSP. Reproducibility was ensured by adhering to the Vitamin D External Quality Assessment Scheme (DEQAS; http:// www.deqas.kpmd.co.uk). The inter-assay and intra-assay CV were 4.7 and $8.0 \%$, respectively.

\section{Questionnaire data}

\section{Ethnicity}

Ethnicity was determined on the basis of self-perception and was assessed by the following question: 'What do you consider yourself to be?' Response options were (i) 'Norwegian', (ii) 'Sami', (iii) 'Kven' and (iv) 'Other; if other, please describe'. Multiple answers were allowed. Based on these answers, we generated three ethnic categories: non-Sami, multi-ethnic Sami and Sami self-perceived ethnicity. The non-Sami group included participants who considered themselves as something other than Sami; that is, Norwegian, Kven, other, or a combination of these. The multi-ethnic Sami group included participants who defined themselves as Sami in combination with any other ethnic group. The Sami group included participants who defined themselves solely as Sami; that is, without reporting any other ethnicities. We excluded participants with backgrounds from non-Western European, Asian and African countries.

\section{Food and nutrient assessment}

The FFQ in the SAMINOR 2 Clinical Survey was a slightly modified version of that used in the Norwegian Women and Cancer (NOWAC) Study ${ }^{(29)}$, with minor adjustments, mainly related to some known traditional food items ${ }^{(30)}$. The NOWAC FFQ has previously been validated for the general female population of Norway and is described in detail elsewhere ${ }^{(30,31)}$. We utilized the NOWAC nutrient calculation program to estimate daily intakes of foods and nutrients, and the Norwegian food composition database (see www.matportalen.no/verktoy/the_norwegian_food_ composition_table/) was used. Total daily dietary intake of vitamin D $(\mu \mathrm{g} / \mathrm{d})$ was calculated. Liquid cod-liver oil supplement (translated as 'bottled cod-liver oil' in the English version of the questionnaire, question nos. 88-90; see www.saminor.no) was estimated in $\mathrm{g} / \mathrm{d}$ and included in the calculation of daily dietary vitamin D intake; however, other supplements were not.

\section{Use of dietary supplements}

Frequency of use of cod-liver oil/fish oil supplements. We considered both liquid cod-liver oil and cod-liver oil capsules/fish oil capsules as cod-liver oil/fish oil supplements. Participants were asked to report their intake of these supplements during winter and during the rest of the year. Participants who took such supplements daily throughout the year were defined as "whole-year daily 
users'. Participants who took cod-liver oil/fish oil supplements daily either during winter or the rest of the year were defined as 'part-year daily users'. Participants who took cod-liver oil/fish oil supplements between one and six days per week either during winter or the rest of the year were defined as 'occasional users'. Participants who never took cod-liver oil/fish oil supplements or took it less frequently than once per week (during winter and the rest of the year) were defined as 'non-users'.

Frequency of use of cod-liver oil capsules/fish oil capsules. We created the variable 'frequency of use of codliver oil capsules/fish oil capsules' for use in analyses that included total daily dietary vitamin D intake, as liquid codliver oil was already included therein. In this way, we could examine the contribution of this factor alone. Participants who took cod-liver oil capsules/fish oil capsules daily during winter and during the rest of the year were defined as 'whole-year daily users'. Participants who took cod-liver oil capsules/fish oil capsules daily either during winter or the rest of the year were defined as 'part-year daily users'. Participants who never took cod-liver oil capsules/fish oil capsules or took it less frequently than once per day (during winter and the rest of the year) were defined as cod-liver oil capsules/fish oil capsules 'nonusers'.

\section{Use of vitamins/minerals}

Participants were asked: 'Do you take food supplements (vitamins/minerals)?' Use of vitamin/mineral supplements other than cod-liver oil/fish oil supplements (yes or no) was estimated and used in the analyses as a dichotomous categorical variable. It was not possible to include vitamins/ minerals and cod-liver oil capsules/fish oil capsules into estimation of daily vitamin D intake due to lack of information on nutrient content in the various products used.

\section{Non-dietary variables}

The questionnaire included questions on education (total number of completed years of education), physical activity (on a scale from 1 to 10) and smoking status. In the analyses, education was categorized as $<13$ years and $\geq 13$ years; physical activity as low (1-3), moderate (4-7) and high (8-10); and smoking status as current, former and never.

Sun exposure was estimated by questions on sunbathing holidays in the past month (yes or no), frequency of solarium use in the past month (no use, 1-2 times per week, $\geq 3$ times per week) and total number of daylight hours outside in the past week. In the analyses, total number of daylight hours outside in the past week was adjusted for the 'dark season' when the intensity of sunlight is insufficient for cutaneous vitamin D production in this geographical area ${ }^{(24)}$ (both missing and reported values were coded as 0 if blood samples were collected between 1 November and 15 February), divided into sexspecific quartiles and used as a categorical variable.

\section{Height and weight}

Height and weight were measured using an electronic Height, Weight \& Fatness Measuring System (DS-103; Dongsahn Jenix, Seoul, Korea) with the participants wearing light clothing and no shoes. Height was measured to the nearest $0 \cdot 1 \mathrm{~cm}$ and weight to the nearest $100 \mathrm{~g}$; and these were then used to calculate BMI in $\mathrm{kg} / \mathrm{m}^{2}$. Obesity was defined as BMI $\geq 30 \cdot 0 \mathrm{~kg} / \mathrm{m}^{2}$.

\section{Register-based variables}

Gender, year of birth and municipality of residence was obtained from the National Register (Folkeregisteret). Age was defined as the age at the end of the year of clinical examination and was divided into three groups: 40-49, 50-59 and 60-69 years. Geographical region of residence was categorized as the inland region (including the municipalities of Karasjok and Kautokeino) and the coastal region (including the other eight municipalities), based on whether the municipalities include coastal areas or not (Fig. 1).

\section{Seasons}

We divided the sample into three groups according to season of blood sample collection: (i) November, JanuaryApril (extended Arctic winter); (ii) May-June; and (iii) September-October.

\section{Exclusions}

We excluded participants with missing information on selfperceived ethnicity ( $n$ 115), non-Western migrants ( $n$ 69), those with incomplete FFQ (more than $50 \%$ blanks, i.e. more than fifty-seven food items without responses; $n$ 91), those with missing height and weight measurements $(n 7)$, over- and under-reporters (participants in the top and bottom $1 \%$ of the ratio of energy intake to BMR; $n$ 90), those with missing s-25(OH)D concentration $(n 37)$ and those with extreme s-25(OH)D concentration (i.e. $>200 \mathrm{nmol} / \mathrm{l}$; $n$ 2). Totally, $8 \%$ ( $n$ 411) of the participants were excluded, thus the final analytical sample consisted of 4465 individuals. The minimum-maximum values of total daily energy intake after exclusion were $3 \cdot 1-22 \cdot 1 \mathrm{MJ}$ in males and $2 \cdot 6-15 \cdot 1 \mathrm{MJ}$ in females.

\section{Statistical analysis}

We present: (i) mean (sD) S-25(OH)D concentration in males and females by month of blood sample collection; (ii) proportions of males and females with S-25(OH)D concentration $<50 \mathrm{nmol} / \mathrm{l}$ by month of blood sample collection; (iii) summary statistics of S-25(OH)D concentrations and the proportion of participants with concentration $<25$, $<30,<50$ and $<75 \mathrm{nmol} / 1$ for the entire sample, by gender and season of blood sample collection; and (iv) mean (SD) S-25(OH)D concentration in males and females by characteristics of the study population. We also show mean (SD) 
and median S-25(OH)D concentrations in non-Sami, multiethnic Sami and Sami ethnic groups by season of blood sample collection and age (see online supplementary material, Supplemental Table S1).

S-25(OH)D concentration cut-offs were chosen based on current definitions of vitamin D deficiency (US Institute of Medicine and other experts $)^{(7,32,33)}$. According to the US Institute of Medicine, persons are at risk of deficiency in terms of the bone health at a S-25(OH)D concentration of $<30 \mathrm{nmol} / \mathrm{l}$; not all persons, but some, are potentially at the risk of inadequacy at a concentration of $30-<50 \mathrm{nmol} / \mathrm{l}$; practically all persons are vitamin D sufficient at a S-25(OH)D concentration of $\geq 50 \mathrm{nmol} / 1^{(7)}$. In Europe it is common to define severe deficiency at S-25(OH)D concentration of $<25 \mathrm{nmol} / \mathrm{l}^{(33)}$. The Endocrine Society in the USA has suggested that to maintain the best effect of vitamin $D$ on metabolism, S-25(OH)D concentration should be $\geq 75 \mathrm{nmol} / \mathrm{l}$; however, this is still being debated ${ }^{(32)}$.

Gender-specific tertiles of total daily dietary vitamin D intake (including liquid cod-liver oil) were created, with the lowest tertile used as the reference group.

First, we applied gender-specific multiple linear regression to assess predictors for S-25(OH)D concentration. Preliminary models included known or suspected determinants of these concentrations, namely age, education, ethnicity, geographical region of residence, smoking status, physical activity, BMI, alcohol intake, seasons, number of daylight hours outside in the past week, sunbathing holiday in the past month, solarium use in the past month, use of vitamins/minerals, use of cod-liver oil capsules/fish oil capsules (because liquid cod-liver oil was included in daily vitamin D intake calculation) and daily vitamin D intake. Backward selection was performed to identify predictors $(P<0 \cdot 05)$. If at least one category was significantly associated with S-25(OH)D concentration, the categorical variable was kept in the final model. The assumptions of the linear regression models were met.
For the final models, the variables age, smoking status, alcohol intake (females), BMI, seasons, sunbathing holiday in the past month, solarium use in the past month, use of vitamins/minerals, use of cod-liver oil capsules/fish oil capsules and daily vitamin D intake were identified as predictors of vitamin D status.

We present models that consider vitamin $\mathrm{D}$ intake as a categorical variable (tertiles) and as a continuous variable to estimate the effect of dietary vitamin D intake $(\mu \mathrm{g} / \mathrm{d})$ on S-25(OH)D concentration. Unstandardized $\beta$ coefficient with $95 \% \mathrm{CI}, P$ value and adjusted $R^{2}$ are reported for multivariable linear regression models.

$R^{2}$ statistics were employed for dominance analysis to explore the relative importance of predictors (\%). General dominance statistic and rank are reported in the online supplementary material, Supplemental Table S2.

Second, we analysed the effect of ethnicity (multi-ethnic Sami $v$. non-Sami (reference) and Sami $v$. non-Sami (reference)) on the probability of having S-25(OH)D concentration $<50$ or $\geq 50 \mathrm{nmol} / 1$ by multivariable logistic models. One model adjusted for age group and month of blood draw; and the other adjusted for age group, month of blood draw, sunbathing holiday, food supplements other than cod-liver oil and vitamin D intake (strong modifiable predictors in males and females). OR with $95 \%$ $\mathrm{CI}$ and $P$ value are reported for logistic regression models.

$P<0.05$ was considered statistically significant and all statistical tests were two-sided. Data were analysed using the statistical software package Stata version 14 .

\section{Results}

\section{Distribution of serum 25-bydroxyvitamin D concentration and sample characteristics}

The distribution of S-25(OH)D concentration varied by month of blood sample collection in males and females

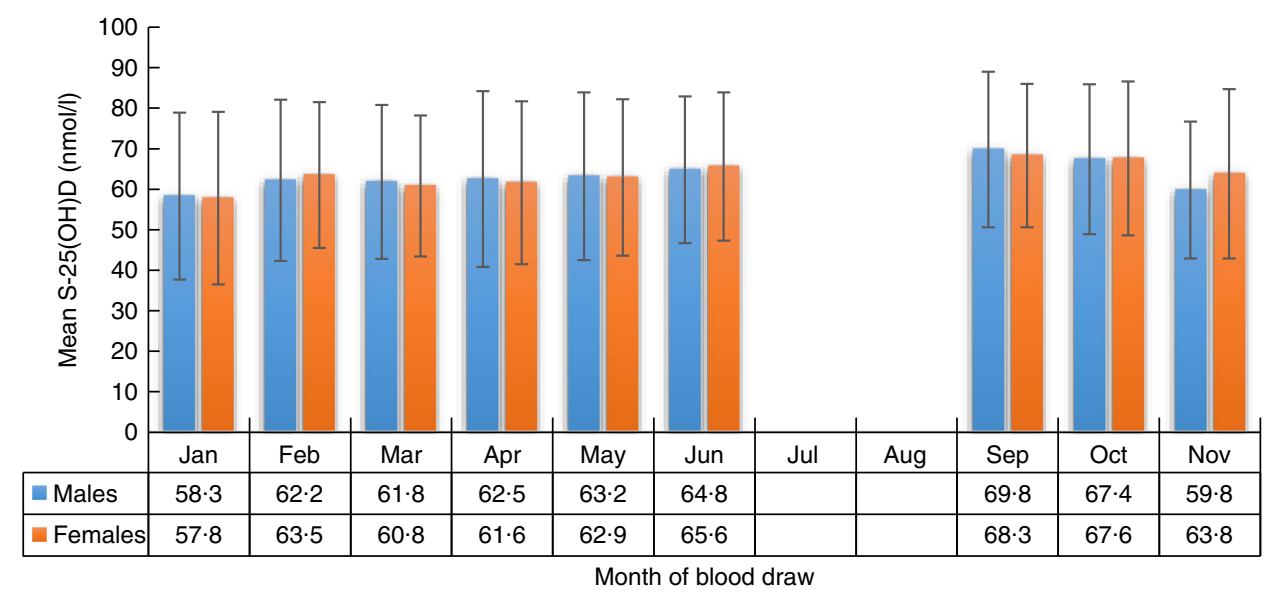

Fig. 2 Serum 25-hydroxyvitamin D (S-25(OH)D) concentration (nmol/l) in males and females, by month of blood draw, in the SAMINOR 2 Clinical Survey of adults aged 40-69 years in northern Norway $\left(68-70^{\circ} \mathrm{N}\right), 2012-2014$ ( $n$ 4465). Values are means with their SD indicated by vertical bars 
(Figs 2 and 3). The lowest mean S-25(OH)D values and percentage of concentrations $<50 \mathrm{nmol} / 1$ were detected in January and the highest in September. The mean S-25(OH)D concentration was 64.0 (SD 19.2) nmol/1, with no differences $(P=0.7)$ between males $(64.1$ (SD 19.7) nmol/l) and females (63.9) (SD 18.8) nmol/1; Table 1).

The mean age in the study sample population was 55.9 (SD 8.5) years, and females were slightly younger $(P=0 \cdot 0001)$. About half of all participants consumed codliver oil/fish oil supplements occasionally or daily. Only $18.2 \%$ of males reported use of vitamins/minerals (other than cod-liver oil/fish oil supplements) compared with $42.3 \%$ of females $(P<0.0001)$. There were fewer teetotallers and a higher alcohol intake among males than among females $(P<0.0001)$. In the entire sample, $11.9 \%$ had been on a sunbathing holiday and $4.6 \%$ had used a solarium during the past month. Females reported solarium use more often $(P<0 \cdot 0001)$ than males; however, an equal percentage of males and females had been on a sunbathing holiday $(\sim 12 \% ; P=0.85)$. Males reported more daylight hours outside $(P<0 \cdot 0001$; Table 2$)$.

The median total daily dietary intake of vitamin D (including liquid cod-liver oil) was $10 \cdot 3 \mu \mathrm{g} / \mathrm{d}$ for the entire sample, $11.6 \mu \mathrm{g} / \mathrm{d}$ among males and $9.2 \mu \mathrm{g} / \mathrm{d}$ among females (Table 2).

Excluded participants did not differ from the study sample in terms of mean concentration of S-25(OH)D and prevalence of deficiency/insufficiency; however, a somewhat higher prevalence of S-25(OH)D deficiency (4.4\%) and insufficiency (35.5\%) was observed among participants in top and bottom $1 \%$ of energy intake:BMR (n 90).
Distribution of ethnic groups according to season

In November and January-April, $46.4 \%$ of participants with Sami, $16.5 \%$ with multi-ethnic Sami and $37 \cdot 1 \%$ with non-Sami self-perceived ethnicity were examined. Fewer participants with Sami (5.7 and 5.3\%) and multi-ethnic Sami $(11.0$ and $11.5 \%)$ than non-Sami ethnicity ( 83.3 and $83.2 \%$ ) were examined in May-June and September-October, respectively $(P<0 \cdot 0001)$.

\section{Predictors of serum 25-bydroxyvitamin $D$ concentration in males and females}

Gender-specific multivariable regression models explained $21-23 \%$ of the variance in circulating S-25(OH)D concentration. Ethnicity did not predict S-25(OH)D concentration in multivariable models. Older age, blood draw in September-October, solarium use in the past month, being on a sunbathing holiday in the past month, higher alcohol intake (in females), more frequent codliver capsules/fish oil capsules use, use of vitamin/ mineral supplements and higher daily intake of vitamin D were significantly associated with higher S-25(OH)D concentration, whereas being a current smoker and obesity were associated with lower S-25(OH)D concentration in males and females (models 1, 2, 3 and 4 in Table 3).

According to the final multivariable regression models, for every additional $1 \mu \mathrm{g} / \mathrm{d}(40 \mathrm{IU} / \mathrm{d})$ increase in dietary vitamin $\mathrm{D}$ intake (including liquid cod-liver oil intake), S-25(OH)D increased by $0.49 \mathrm{nmol} / 1$ in males and by $0.51 \mathrm{nmol} / 1$ in females (models 2 and 4 in Table 3).

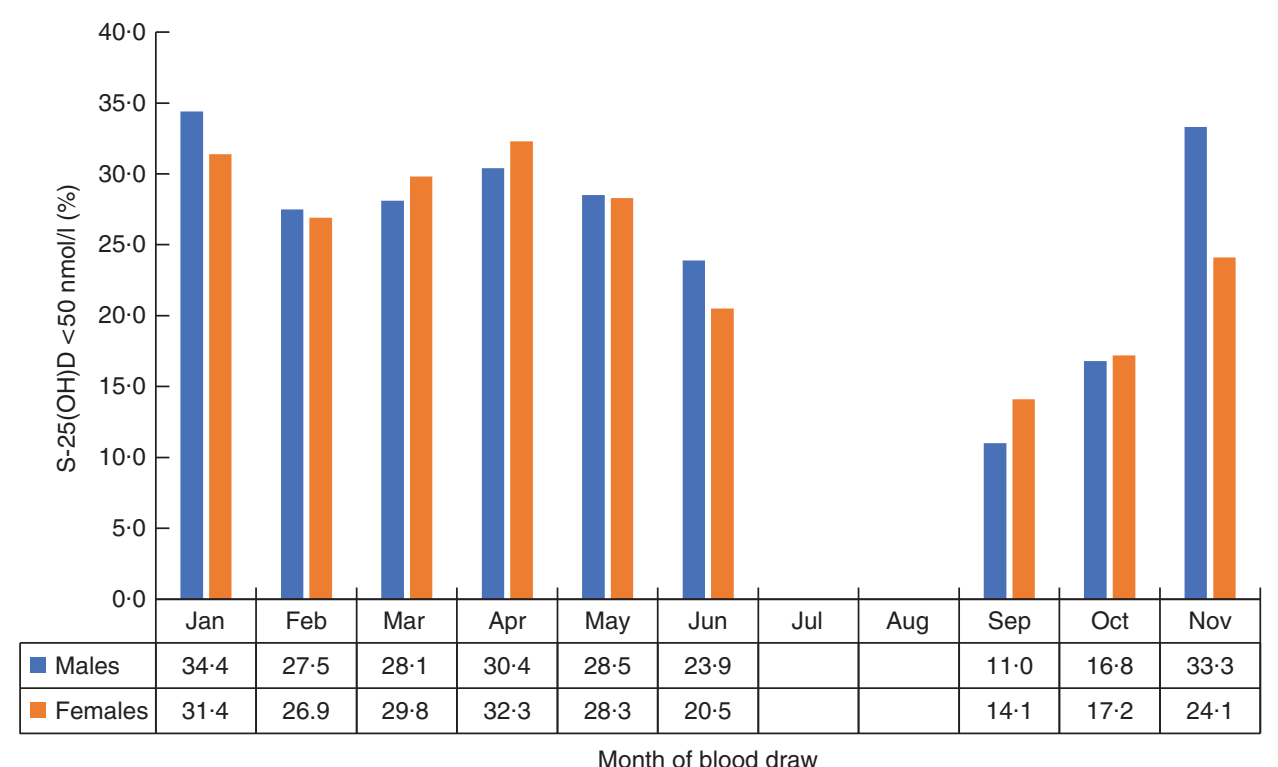

Fig. 3 Percentage with 25-hydroxyvitamin D (S-25(OH)D) concentration $<50 \mathrm{nmol} / \mathrm{l}$ in males and females, by month of blood draw, in the SAMINOR 2 Clinical Survey of adults aged 40-69 years in northern Norway $\left(68-70^{\circ} \mathrm{N}\right), 2012-2014$ ( $n$ 4465) 
Vitamin D status in rural northern Norway

Table 1 Distribution of serum 25-hydroxyvitamin D (S-25(OH)D) concentration (nmol/l) in relation to season and gender in the SAMINOR 2 Clinical Survey of adults aged $40-69$ years in Northern Norway $\left(68-70^{\circ} \mathrm{N}\right)$, 2012-2014 ( $n$ 4465)

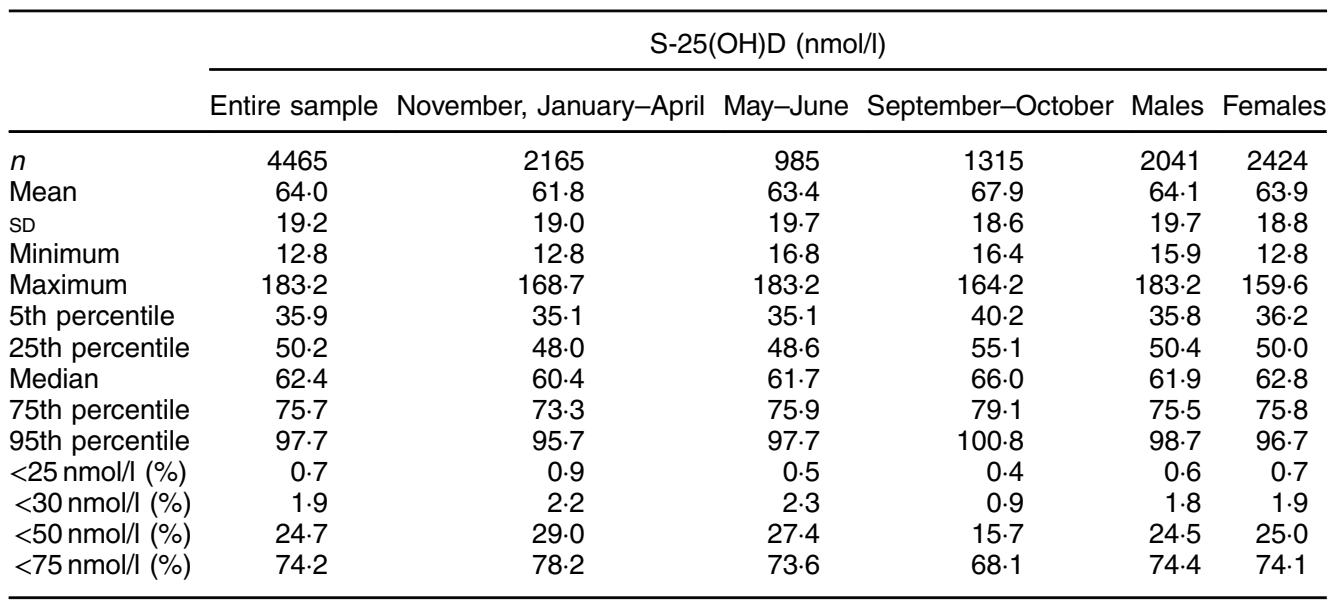

Multivariable logistic regression models in males and females to assess ethnic differences in the prevalence of serum 25-hydroxyvitamin $D<50 \mathrm{nmol} / \mathrm{l}$

In our sample, S-25(OH)D concentration $<50 \mathrm{nmol} / \mathrm{l}$ was detected in $22.8 \%$ of males and $22.3 \%$ females with nonSami, $26.7 \%$ males and $27 \cdot 7 \%$ females with multi-ethnic, and in $27.2 \%$ males and $29.9 \%$ females with Sami selfperceived ethnicity (Table 4). Ethnicity was not associated with S-25(OH)D concentration in males. After adjustment for age and month of blood sample collection, females with Sami self-perceived ethnicity had $30 \%$ reduced odds to have sufficient S-25(OH)D concentration $(\geq 50 \mathrm{nmol} / \mathrm{l})$ compared with non-Sami females (model 1 in Table 4). However, after adjustment for additional variables (age group, month of blood draw, sunbathing holiday in the past month, use of supplements other than cod-liver oil and vitamin D intake), the association was no longer significant (model 2 in Table 4).

\section{Discussion}

The present study investigates vitamin D status in a large multi-ethnic cohort of 4465 individuals aged 40-69 years, including $25 \%$ of participants with self-perceived Sami ethnicity and $14 \%$ of participants with self-perceived multi-ethnic ethnicity from a comprehensive rural area of northern Norway. The results show that, overall, the proportion of participants with non-optimal vitamin D concentration (i.e. $<50 \mathrm{nmol} / \mathrm{l}$ ) was nearly $25 \%$; however, only $2 \%$ had a vitamin D concentration $<30 \mathrm{nmol} / 1$ (i.e. severe hypovitaminosis D). Among all predictors, dietary vitamin D intake (including liquid cod-liver oil) and having gone on a sunbathing holiday in the past month were the strongest contributors to maintain optimal vitamin D status in males and females.

Very few individuals had S-25(OH)D concentration $<30 \mathrm{nmol} / 1$ in all ethnic groups, and this was a striking finding. In fact, this finding is consistent with previous results reported in Nordic countries among populations living close to the Arctic Circle ${ }^{(34)}$. We found that the population of rural northern Norway has a more favourable vitamin $\mathrm{D}$ status than mid-European populations despite limited sun exposure ${ }^{(8,19)}$. The factors behind this low prevalence of vitamin D deficiency are likely to include significantly higher dietary vitamin D intake and frequent vitamin D supplementation. However, other factors like paler skin pigmentation in Northerners ${ }^{(35)}$, sun holidays and different sun-seeking behaviours, and genetic polymorphism could also influence vitamin D status.

Circulating 25(OH)D in the Indigenous Sami in Norway has not been previously studied. We showed no ethnic differences in the prevalence of S-25(OH)D concentration $\geq 50 \mathrm{nmol} / 1$ in males. Sami females, compared with non-Sami females, had a $30 \%$ reduced chance of having an optimal S-25(OH)D concentration of $\geq 50 \mathrm{nmol} / 1$ after adjustment for age and month of blood sample collection. However, this weak association disappeared when modifiable lifestyle covariates were included in the regression model.

It should be mentioned that sampling in inland areas, where the majority of the population is Sami (Karasjok and Kautokeino), was performed in January, February and March. During these months, UV-induced vitamin D production is limited or absent, leading to a drop in S-25(OH)D concentration, following well-known seasonal fluctuation. Indeed, blood sample collection in September-October was positively associated with higher S-25(OH)D concentration, and the prevalence of concentration $<50 \mathrm{nmol} / \mathrm{l}$ was 


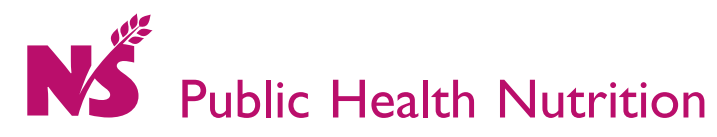

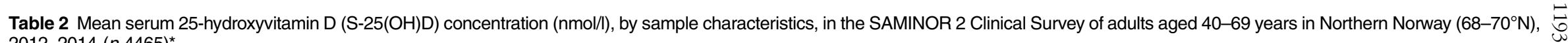
2012-2014 (n 4465)

\begin{tabular}{|c|c|c|c|c|c|c|c|c|c|}
\hline & \multicolumn{4}{|c|}{ Males ( $n$ 2041) } & \multicolumn{4}{|c|}{ Females ( $n$ 2424) } & \multirow[b]{3}{*}{$P \dagger$} \\
\hline & \multicolumn{2}{|c|}{ Characteristic } & \multicolumn{2}{|c|}{$\mathrm{S}-25(\mathrm{OH}) \mathrm{D}(\mathrm{nmol} / \mathrm{l})$} & \multicolumn{2}{|c|}{ Characteristic } & \multicolumn{2}{|c|}{$\mathrm{S}-25(\mathrm{OH}) \mathrm{D}(\mathrm{nmol} / \mathrm{l})$} & \\
\hline & Mean, SD or $n$ & Median or $\%$ & Mean & SD & Mean, SD or $n$ & Median or $\%$ & Mean & SD & \\
\hline $\begin{array}{l}\text { Age (years) } \\
\text { SD }\end{array}$ & $\begin{array}{r}56 \cdot 5 \\
8.4\end{array}$ & $58 \cdot 0$ & & & $\begin{array}{r}55 \cdot 5 \\
8.6\end{array}$ & $56 \cdot 0$ & & & 0.0001 \\
\hline \multicolumn{10}{|l|}{ Age (years), $n$ and \% } \\
\hline $\begin{array}{l}40-49 \\
50-59 \\
60-69\end{array}$ & $\begin{array}{l}515 \\
647 \\
879\end{array}$ & $\begin{array}{l}25 \cdot 2 \\
31 \cdot 7 \\
43 \cdot 1\end{array}$ & $\begin{array}{l}58 \cdot 0 \\
64 \cdot 3 \\
67 \cdot 5\end{array}$ & $\begin{array}{l}18 \cdot 3 \\
19 \cdot 7 \\
19 \cdot 7\end{array}$ & $\begin{array}{l}686 \\
806 \\
932\end{array}$ & $\begin{array}{l}28 \cdot 3 \\
33 \cdot 3 \\
38 \cdot 4\end{array}$ & $\begin{array}{l}57 \cdot 7 \\
64 \cdot 4 \\
68 \cdot 0\end{array}$ & $\begin{array}{l}18 \cdot 0 \\
18 \cdot 1 \\
18 \cdot 7\end{array}$ & 0.005 \\
\hline $\begin{array}{l}\text { Education (years) } \\
\text { SD }\end{array}$ & $\begin{array}{r}12 \cdot 2 \\
3.5\end{array}$ & $12 \cdot 0$ & & & $\begin{array}{r}13 \cdot 2 \\
3 \cdot 9\end{array}$ & $13 \cdot 0$ & & & $<0.0001$ \\
\hline \multicolumn{10}{|l|}{ Education (years), $n$ and $\%$} \\
\hline$<13$ & 1156 & $58 \cdot 4$ & $64 \cdot 1$ & $20 \cdot 1$ & 1113 & $47 \cdot 6$ & $64 \cdot 8$ & $19 \cdot 1$ & \multirow[t]{2}{*}{$<0.0001$} \\
\hline \multicolumn{9}{|l|}{ Self-perceived ethnicity, $n$ and \% } & \\
\hline Non-Sami & 1238 & $60 \cdot 7$ & $64 \cdot 9$ & $20 \cdot 2$ & 1480 & $61 \cdot 1$ & $65 \cdot 3$ & $19 \cdot 1$ & \multirow[t]{3}{*}{0.95} \\
\hline Multi-ethnic Sami & 285 & 14.0 & $64 \cdot 0$ & 19.6 & 332 & 13.7 & $62 \cdot 1$ & $18 \cdot 3$ & \\
\hline Sami & 518 & $25 \cdot 4$ & $62 \cdot 2$ & $18 \cdot 6$ & 612 & $25 \cdot 2$ & $61 \cdot 6$ & $18 \cdot 1$ & \\
\hline \multicolumn{10}{|l|}{ Geographical region, $n$ and $\%$} \\
\hline Inland & 429 & $21 \cdot 0$ & $60 \cdot 0$ & $17 \cdot 5$ & 563 & 23.2 & $61 \cdot 1$ & $17 \cdot 3$ & \multirow[t]{2}{*}{0.08} \\
\hline Coastal & 1612 & $79 \cdot 0$ & $65 \cdot 2$ & $20 \cdot 1$ & 1861 & $76 \cdot 8$ & 64.8 & $19 \cdot 1$ & \\
\hline \multicolumn{10}{|l|}{ Smoking status, $n$ and $\%$} \\
\hline Never & 715 & $35 \cdot 2$ & 63.7 & 18.5 & 878 & $36 \cdot 7$ & $64 \cdot 3$ & $18 \cdot 1$ & \multirow{3}{*}{$<0.0001$} \\
\hline Former & 944 & $46 \cdot 5$ & $66 \cdot 1$ & $20 \cdot 2$ & 978 & $40 \cdot 8$ & $65 \cdot 8$ & $19 \cdot 0$ & \\
\hline Current & 370 & $18 \cdot 2$ & 59.9 & $20 \cdot 1$ & 539 & 22.5 & $59 \cdot 6$ & $18 \cdot 7$ & \\
\hline \multicolumn{10}{|l|}{ Physical activity (levels), $n$ and $\%$} \\
\hline Low $(1-3)$ & 424 & $21 \cdot 1$ & $62 \cdot 4$ & $21 \cdot 2$ & 414 & $17 \cdot 7$ & 61.5 & $18 \cdot 7$ & \multirow[t]{2}{*}{$<0.0001$} \\
\hline Moderate (4-7) & 1287 & $64 \cdot 2$ & 63.9 & $19 \cdot 2$ & 1491 & 63.7 & $64 \cdot 2$ & $18 \cdot 8$ & \\
\hline High $(8-10)$ & 295 & 14.7 & 67.4 & $19 \cdot 2$ & 436 & $18 \cdot 6$ & $65 \cdot 2$ & $19 \cdot 0$ & \\
\hline BMI $\left(\mathrm{kg} / \mathrm{m}^{2}\right)$ & $28 \cdot 4$ & $27 \cdot 9$ & & & $27 \cdot 8$ & $26 \cdot 9$ & & & $<0.0001$ \\
\hline SD & $4 \cdot 1$ & & & & 4.9 & & & & \\
\hline \multicolumn{10}{|l|}{ BMI $\left(\mathrm{kg} / \mathrm{m}^{2}\right), n$ and $\%$} \\
\hline$<30$ & 1444 & $70 \cdot 7$ & $65 \cdot 6$ & $19 \cdot 9$ & 1744 & 71.9 & $64 \cdot 8$ & $19 \cdot 3$ & \multirow[t]{2}{*}{0.38} \\
\hline$\geq 30$, obese & 597 & $29 \cdot 3$ & $60 \cdot 5$ & $19 \cdot 0$ & 680 & $28 \cdot 1$ & 61.5 & $17 \cdot 3$ & \\
\hline Alcohol intake, non-consumers included $(\mathrm{g} / \mathrm{d})$ & $5 \cdot 3$ & $2 \cdot 7$ & & & $2 \cdot 8$ & $1 \cdot 3$ & & & \multirow[t]{2}{*}{$<0.0001 \S$} \\
\hline SD & $7 \cdot 1$ & & & & $4 \cdot 0$ & & & & \\
\hline $\begin{array}{l}\text { Alcohol intake }(\mathrm{g} / \mathrm{d}), n \text { and } \% \\
0, \text { non-consumers }\end{array}$ & 354 & $17 \cdot 3$ & $60 \cdot 9$ & $17 \cdot 6$ & Alcohol intake $(\mathrm{g} / \mathrm{d}), n$ and $\%$ & $26 \cdot 2$ & $61 \cdot 6$ & 17.5 & \multirow{3}{*}{$<0.0001$} \\
\hline$<6$ & 1102 & $54 \cdot 0$ & $64 \cdot 3$ & $20 \cdot 0$ & 1466 & 60.5 & $64 \cdot 2$ & 18.7 & \\
\hline$\geq 6$ & 585 & $28 \cdot 7$ & 65.5 & $20 \cdot 3$ & 323 & $13 \cdot 3$ & $67 \cdot 2$ & 20.9 & \\
\hline \multicolumn{10}{|l|}{ Season of the blood collection, $n$ and \% } \\
\hline November, January-April & 970 & 47.5 & $61 \cdot 8$ & $19 \cdot 7$ & 1195 & $49 \cdot 3$ & $61 \cdot 8$ & 18.4 & 0.46 \\
\hline May-June & 454 & $22 \cdot 2$ & 63.5 & $20 \cdot 3$ & 531 & 21.9 & $63 \cdot 3$ & $19 \cdot 1$ & \\
\hline September-October & 617 & $30 \cdot 2$ & $68 \cdot 1$ & $18 \cdot 7$ & 698 & $28 \cdot 8$ & $67 \cdot 8$ & $18 \cdot 6$ & \\
\hline $\begin{array}{l}\text { Daylight hours outside in the past week } \\
\text { SD }\end{array}$ & $\begin{array}{l}20 \cdot 8 \\
19 \cdot 4\end{array}$ & $15 \cdot 0$ & & & $\begin{array}{l}10 \cdot 3 \\
10 \cdot 8\end{array}$ & $7 \cdot 0$ & & & $<0.0001 \S$ \\
\hline
\end{tabular}




\section{Nes Public Health Nutrition}

Table 2 Continued

\begin{tabular}{|c|c|c|c|c|c|c|c|c|c|}
\hline & \multicolumn{4}{|c|}{ Males $(n$ 2041) } & \multicolumn{4}{|c|}{ Females ( $n$ 2424) } & \multirow[b]{3}{*}{$P \dagger$} \\
\hline & \multicolumn{2}{|c|}{ Characteristic } & \multicolumn{2}{|c|}{$\mathrm{S}-25(\mathrm{OH}) \mathrm{D}(\mathrm{nmol} / \mathrm{l})$} & \multicolumn{2}{|c|}{ Characteristic } & \multicolumn{2}{|c|}{$\mathrm{S}-25(\mathrm{OH}) \mathrm{D}(\mathrm{nmol} / \mathrm{l})$} & \\
\hline & Mean, sD or $n$ & Median or $\%$ & Mean & SD & Mean, sD or $n$ & Median or \% & Mean & SD & \\
\hline \multicolumn{10}{|c|}{ Daylight hours outside in the past week, $n$ and \% } \\
\hline Quartile 1 & 476 & $25 \cdot 3$ & $62 \cdot 4$ & $19 \cdot 3$ & 624 & 29.5 & 60.9 & $18 \cdot 2$ & \\
\hline Quartile 2 & 512 & $27 \cdot 3$ & 64.6 & $20 \cdot 7$ & 469 & $22 \cdot 2$ & 64.0 & $17 \cdot 7$ & \\
\hline Quartile 3 & 479 & 25.5 & 64.4 & $19 \cdot 0$ & 526 & 24.9 & 65.5 & $18 \cdot 7$ & \\
\hline Quartile 4 & 411 & 21.9 & $66 \cdot 1$ & 19.4 & 494 & 23.4 & 65.1 & $19 \cdot 3$ & \\
\hline \multicolumn{10}{|c|}{ Sunbathing holiday in the past month, $n$ and $\%$} \\
\hline Yes & 244 & $12 \cdot 0$ & $77 \cdot 0$ & $23 \cdot 0$ & 285 & 11.8 & 74.0 & 18.5 & 0.85 \\
\hline No & 1784 & 88.0 & $62 \cdot 3$ & $18 \cdot 6$ & 2121 & 88.2 & 62.5 & 18.4 & \\
\hline \multicolumn{10}{|c|}{ Solarium use in the past month, $n$ and $\%$} \\
\hline No & 1974 & $97 \cdot 6$ & 63.8 & 19.7 & 2239 & $93 \cdot 6$ & 63.3 & $18 \cdot 7$ & $<0.0001$ \\
\hline $1-2$ times & 33 & 1.6 & $73 \cdot 1$ & $17 \cdot 2$ & 116 & 4.9 & 72.0 & 17.9 & \\
\hline$\geq 3$ times & 15 & 0.7 & $79 \cdot 4$ & $20 \cdot 3$ & 36 & 1.5 & $76 \cdot 3$ & $16 \cdot 8$ & \\
\hline \multicolumn{10}{|c|}{ Use of vitamin/mineral supplements, $n$ and $\%$} \\
\hline Users & 360 & $18 \cdot 2$ & $72 \cdot 0$ & $20 \cdot 1$ & 993 & $42 \cdot 3$ & 68.4 & 18.9 & $<0.0001$ \\
\hline Non-users & 1622 & 81.8 & $62 \cdot 2$ & $19 \cdot 1$ & 1353 & $57 \cdot 7$ & $60 \cdot 8$ & $18 \cdot 1$ & \\
\hline \multicolumn{10}{|c|}{ Cod-liver oil/fish oil supplements, $n$ and $\%$} \\
\hline Non-users & 1064 & $52 \cdot 3$ & $59 \cdot 1$ & $19 \cdot 0$ & 1077 & $44 \cdot 6$ & 58.9 & $18 \cdot 3$ & $<0.0001$ \\
\hline Occasional users, $\geq 1 /$ week & 256 & $12 \cdot 6$ & $64 \cdot 1$ & $18 \cdot 6$ & 277 & 11.5 & $61 \cdot 2$ & $17 \cdot 3$ & \\
\hline Part-year daily users & 233 & 11.4 & $70 \cdot 3$ & $19 \cdot 4$ & 402 & $16 \cdot 7$ & $67 \cdot 3$ & $17 \cdot 0$ & \\
\hline Whole-year daily users & 482 & 23.7 & $72 \cdot 3$ & 18.5 & 657 & $27 \cdot 2$ & 71.0 & $18 \cdot 6$ & \\
\hline \multicolumn{10}{|c|}{ Cod-liver oil capsules/fish oil capsules, $n$ and $\%$} \\
\hline Non-users/occasional users, $<1 / \mathrm{d}$ & 1419 & $79 \cdot 1$ & $64 \cdot 1$ & $20 \cdot 0$ & 1500 & $68 \cdot 8$ & $63 \cdot 3$ & $19 \cdot 1$ & $<0.0001$ \\
\hline Part-year daily users & 113 & $6 \cdot 3$ & $66 \cdot 4$ & $18 \cdot 3$ & 244 & $11 \cdot 2$ & 63.5 & $16 \cdot 7$ & \\
\hline Whole-year daily users & 262 & $14 \cdot 6$ & 69.5 & 18.7 & 436 & $20 \cdot 0$ & 68.5 & 18.4 & \\
\hline Vitamin D intake $(\mu \mathrm{g} / \mathrm{d})$ & 14.7 & 11.6 & & & $12 \cdot 1$ & $9 \cdot 2$ & & & $<0.0001 \S$ \\
\hline SD & 9.5 & & & & 8.7 & & & & \\
\hline \multicolumn{10}{|l|}{ Vitamin D intake $(\mu \mathrm{g} / \mathrm{d}), n$ and $\%$} \\
\hline Tertile 1 & 681 & 33.4 & 58.6 & $19 \cdot 6$ & 808 & $33 \cdot 3$ & 59.5 & $18 \cdot 8$ & \\
\hline Tertile $2 \ddagger$ & 680 & $33 \cdot 3$ & 62.5 & $18 \cdot 7$ & 808 & $33 \cdot 3$ & 62.5 & $17 \cdot 8$ & \\
\hline Tertile $3 \ddagger$ & 680 & $33 \cdot 3$ & $71 \cdot 1$ & $18 \cdot 7$ & 808 & 33.3 & 69.7 & $18 \cdot 2$ & \\
\hline
\end{tabular}

*Subgroups may not total 4465 due to missing values.

†Differences between males and females were tested by Pearson's $x^{2}$ test or the independent-samples $t$ test for normally distributed variables.

$\neq$ Cut-off points between tertile 1 and tertile 2 are $9.1 \mu \mathrm{g} / \mathrm{d}$ for males and $7.1 \mu \mathrm{g} / \mathrm{d}$ for females; cut-off points between tertile 2 and tertile 3 are $15.8 \mu \mathrm{g} / \mathrm{d}$ for males and $12.3 \mu \mathrm{g} / \mathrm{d}$ for females.

$\S M a n n-W h i t n e y ~ U$ test for non-normal data. 


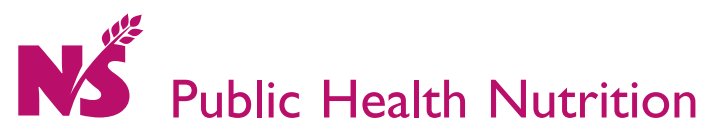

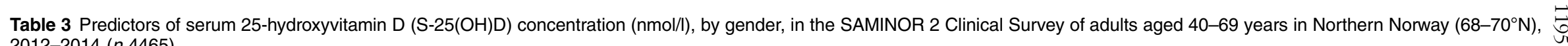
2012-2014 ( $n$ 4465)

\begin{tabular}{|c|c|c|c|c|c|c|c|c|c|c|c|c|}
\hline & \multicolumn{6}{|c|}{ Males } & \multicolumn{6}{|c|}{ Females } \\
\hline & \multicolumn{3}{|c|}{ Model $1^{*}$} & \multicolumn{3}{|c|}{ Model $2 \dagger$} & \multicolumn{3}{|c|}{ Model 3ł } & \multicolumn{3}{|c|}{ Model $4 \S$} \\
\hline & $\beta$ & $95 \% \mathrm{Cl}$ & $P$ & $\beta$ & $95 \% \mathrm{Cl}$ & $P$ & $\beta$ & $95 \% \mathrm{Cl}$ & $P$ & $\beta$ & $95 \% \mathrm{Cl}$ & $P$ \\
\hline \multicolumn{13}{|l|}{ Age (years) } \\
\hline & & Ref. & - & & Ref. & $-\overline{0}$ & & Ref. & $-\overline{0} 01$ & & Ref. & $-\overline{0} 01+100$ \\
\hline $\begin{array}{l}50-59 \\
60-69\end{array}$ & $\begin{array}{l}4.39 \\
6.07\end{array}$ & $\begin{array}{l}2.14,6.65 \\
3.91,8.23\end{array}$ & $\begin{array}{r}0.0001 \\
<0.0001\end{array}$ & $\begin{array}{l}4.51 \\
6 \cdot 16\end{array}$ & $\begin{array}{l}2 \cdot 27,6 \cdot 75 \\
4.02,8 \cdot 31\end{array}$ & $\begin{array}{r}0.0001 \\
<0.0001\end{array}$ & $\begin{array}{l}6.28 \\
9.24\end{array}$ & $\begin{array}{l}4.42,8 \cdot 14 \\
7 \cdot 40,11 \cdot 08\end{array}$ & $\begin{array}{l}<0.0001 \\
<0.0001\end{array}$ & $\begin{array}{l}6.31 \\
9.03\end{array}$ & $\begin{array}{l}4.47,8.14 \\
7.21,10.85\end{array}$ & $\begin{array}{l}<0.0001 \\
<0.0001\end{array}$ \\
\hline Smoking status & & & & & & & & & & & & \\
\hline Never & & Ref. & - & & Ref. & - & & Ref. & - & & Ref. & - \\
\hline $\begin{array}{l}\text { Current } \\
\text { Former }\end{array}$ & $\begin{array}{r}-2.92 \\
1.45\end{array}$ & $-5.36,-0.48$ & 0.02 & $\begin{array}{r}-2.91 \\
1.55\end{array}$ & $\begin{array}{l}-5.34,-0.49 \\
-0.33,3.42\end{array}$ & 0.02 & $\begin{array}{r}-4.16 \\
-077\end{array}$ & $-6.15,-2.17$ & $<0.0001$ & $\begin{array}{r}-4.11 \\
-177\end{array}$ & $-6.08,-2.15$ & $<0.0001$ \\
\hline $\begin{array}{l}\text { Former } \\
\mathrm{BMI}\left(\mathrm{kg} / \mathrm{m}^{2}\right)\end{array}$ & 1.45 & $-0.43,3.33$ & 0.13 & 1.55 & $-0.33,3.42$ & & & & & & & 0.36 \\
\hline$<30$ & & Ref. & - & & Ref. & - & & Ref. & - & & Ref. & - \\
\hline$\geq 30$, obese & $-4 \cdot 24$ & $-6 \cdot 11,-2.37$ & $<0.0001$ & $-4 \cdot 47$ & $-6 \cdot 33,-2 \cdot 61$ & $<0.0001$ & -3.94 & $-5.57,-2.30$ & $<0.0001$ & -3.91 & $-5 \cdot 53,-2 \cdot 28$ & $<0.0001$ \\
\hline $\begin{array}{l}\text { Alcohol intake }(\mathrm{g} / \mathrm{d}) \\
0, \text { non-consumers }\end{array}$ & - & - & - & - & - & - & & & - & & & - \\
\hline$<6$ & - & - & - & - & - & - & 1.44 & $-0.32,3.19$ & 0.11 & 1.64 & $-0.09,3.38$ & 0.06 \\
\hline$\geq 6$ & - & - & - & - & - & - & 3.75 & $1.27,6.23$ & 0.003 & 3.63 & $1.18,6.08$ & 0.004 \\
\hline \multirow{5}{*}{$\begin{array}{l}\text { Season of blood collection } \\
\text { November, January-April } \\
\text { May-June } \\
\text { September-October } \\
\text { Sunbathing holiday in the past month } \\
\text { No } \\
\text { Yes }\end{array}$} & & & & & & & & & & & & \\
\hline & & Ref. & - & & Ref. & - & & Ref. & - & & Ref. & - \\
\hline & 0.63 & $-1.54,2.81$ & 0.57 & 0.60 & $-1.56,2.77$ & 0.59 & -0.02 & $-1.91,1.87$ & 0.99 & -0.004 & $-1.87,1.87$ & 1.0 \\
\hline & 4.80 & $2 \cdot 84,6 \cdot 75$ & $<0.0001$ & 4.80 & $2 \cdot 86,6 \cdot 75$ & $<0.0001$ & 3.64 & $1.92,5 \cdot 36$ & $<0.0001$ & 3.57 & $1 \cdot 87,5 \cdot 27$ & $<0.0001$ \\
\hline & & & - & & & - & & Ref. & - & & Ref. & - \\
\hline \multirow{2}{*}{$\begin{array}{l}\text { Solarium use in the past month } \\
\text { No }\end{array}$} & 14.79 & $12 \cdot 23,17 \cdot 35$ & $<0.0001$ & $15 \cdot 16$ & $12 \cdot 60,17 \cdot 71$ & $<0.0001$ & 9.93 & $7 \cdot 68,12 \cdot 19$ & $<0.0001$ & 9.90 & $7 \cdot 67,12 \cdot 13$ & $<0.0001$ \\
\hline & & Ref. & - & & Ref. & - & & Ref. & - & & Ref. & - \\
\hline \multirow{7}{*}{$\begin{array}{l}1-2 \text { times } \\
\geq 3 \text { times } \\
\text { Vitamin/mineral supplements } \\
\text { Users } \\
\text { Non-users } \\
\text { Cod-liver oil capsules/fish oil capsules } \\
\text { Non-users/occasional users, }<1 / d \\
\text { Part-year daily users } \\
\text { Whole-year daily users }\end{array}$} & 11.70 & $4.96,18.43$ & 0.0007 & 12.69 & $5.99,19.39$ & 0.0002 & 10.23 & $6.92,13.53$ & $<0.0001$ & 10.36 & $7.08,13.63$ & $<0.0001$ \\
\hline & 14.94 & $5 \cdot 60,24 \cdot 28$ & 0.002 & $15 \cdot 58$ & $6 \cdot 28,24 \cdot 87$ & 0.001 & 9.62 & $3.71,15.53$ & 0.001 & $10 \cdot 21$ & $4.36,16.06$ & 0.0006 \\
\hline & & Ref. & - & & & - & & & - & & & - \\
\hline & -5.76 & $7.96,-3.57$ & $<0.0001$ & -5.51 & $-7 \cdot 70,-3 \cdot 32$ & $<0.0001$ & -5.54 & $-7.07,-4.02$ & $<0.0001$ & -5.33 & $-6.83,-3.82$ & $<0.0001$ \\
\hline & & & $\ldots$ & & & - & & & - & & & - \\
\hline & 0.32 & $-3 \cdot 16,3 \cdot 79$ & $0 . \overline{8} 6$ & 0.25 & $-3 \cdot 20,3 \cdot 71$ & 0.87 & 0.26 & $-2 \cdot 12,2.64$ & 0.83 & 0.86 & $-1.51,3.23$ & $0 . \overline{48}$ \\
\hline & 3.60 & $1.12,6.08$ & 0.004 & 3.77 & $1 \cdot 30,6 \cdot 24$ & 0.003 & $2 \cdot 81$ & $0.89,4.73$ & 0.004 & $3 \cdot 10$ & $1 \cdot 20,5.00$ & 0.001 \\
\hline \multirow{4}{*}{$\begin{array}{l}\text { Vitamin D intake }(\mu \mathrm{g} / \mathrm{d}) \\
\text { Tertile } 1 \\
\text { Tertile } 2 \\
\text { Tertile } 3 \\
\text { Vitamin D intake }(\mu \mathrm{g} / \mathrm{d})\end{array}$} & & Bef & - & _ & - & - & & Ref & - & - & - & - \\
\hline & 4.04 & ${ }_{1.93,6.14}$ & $<0.0001$ & - & $=$ & $=$ & 1.99 & $0.19,3.80$ & $0 . \overline{0}$ & $=$ & $=$ & - \\
\hline & 10.76 & $8.69,12.83$ & $<0.0001$ & - & - & - & 8.87 & $7.07,10.68$ & $<0.0001$ & - & - & - \\
\hline & & & & 0.49 & $0.40,0.57$ & $<0.0001$ & & & & 0.51 & $0.43,0.59$ & $<0.0001$ \\
\hline $\begin{array}{l}\text { Constant } \\
\text { Observations } \\
\text { Adjusted } R^{2}\end{array}$ & & $\begin{array}{l}71.89 \\
1719 \\
0.21\end{array}$ & & & $\begin{array}{l}69.73 \\
1719 \\
0.22\end{array}$ & & & $\begin{array}{l}64.83 \\
2065 \\
0.21\end{array}$ & & & $\begin{array}{l}61.86 \\
2065 \\
0.23\end{array}$ & \\
\hline
\end{tabular}

Ref., reference category.

"Model 1 in males predictors include: age (categorical), smoking status (categorical), BMI (categorical), seasons (categorical), sunbathing holiday (categorical), solarium use (categorical), food supplements other than codliver oil (categorical), use of cod-liver oil capsules/fish oil capsules (categorical) and vitamin D intake (categorical).

†Model 2 in males predictors include: age (categorical), smoking status (categorical), BMI (categorical), season (categorical), sunbathing holiday (categorical), solarium use (categorical), food supplements other than codliver oil (categorical), use of cod-liver oil capsules/fish oil capsules (categorical) and vitamin D intake (continuous).

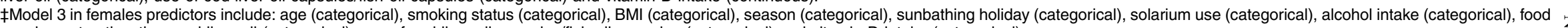
supplements other than cod-liver oil (categorical), use of cod-liver oil capsules/fish oil capsules (categorical) and vitamin D intake (categorical).

\$Model 4 in females predictors include: age (categorical), smoking status (categorical), BMI (categorical), season (categorical), sunbathing holiday (categorical), solarium use (categorical), alcohol intake (categorical), food supplements other than cod-liver oil (categorical), use of cod-liver oil capsules/fish oil capsules (categorical) and vitamin D intake (continuous). 
lower in September-October compared with NovemberJune. Thus, hypovitaminosis D might be overestimated in our Sami participants. In the present study, blood samples were not collected in July and August, when sun exposure is at its highest; therefore we might have overestimated the prevalence of insufficient $\mathrm{S}-25(\mathrm{OH}) \mathrm{D}$ in the entire sample on average in the year, and in the summer season as well. Seasonal variation was, however, small compared with that reported in Central Europe, and it was in line with data from northern Norway ${ }^{(19,36)}$.

Due to nutrition transition, especially among the younger generations, certain aboriginal populations living in the Arctic have a high risk of poor vitamin D status ${ }^{(37)}$. Data from Greenland (the Inuit Health in Transition study) demonstrated a considerable decrease in S-25(OH)D concentration from 1987 to 2005-2010 (in both periods blood was drawn in May-June) ${ }^{(38)}$, with an average $\mathrm{S}-25(\mathrm{OH}) \mathrm{D}$ in $2005-2010$ of $34 \mathrm{nmol} / 1$ and $33 \mathrm{nmol} / \mathrm{l}$ among 18-29-year-old males and females, respectively, and $50 \mathrm{nmol} / \mathrm{l}$ among the 50-69-year-old males and females. In the present study, average S-25(OH)D concentrations of Sami males and females $(62 \mathrm{nmol} / 1)$, multiethnic Sami males $(64 \mathrm{nmol} / \mathrm{l})$ and multi-ethnic Sami females $(62 \mathrm{nmol} / \mathrm{l})$ were satisfactory.

Vitamin D status was associated with intake of daily dietary vitamin $\mathrm{D}$ in a previous paper on factors associated with $25(\mathrm{OH}) \mathrm{D}$ in Norwegian women ${ }^{(4)}$ and thus we expected that this could also be an important factor in our study. We included ethnicity in the present study due to its assumed influence on dietary traditions and habits. However, the identification of ethnic groups in multi-ethnic population-based studies is challenging, as there are no standardized and validated methods. Diet and dietary traditions are often described as important carriers, markers and tools for cultural and ethnic identity and belonging. Therefore, we found it relevant to categorize ethnicity based on self-perception. We distinguished between participants who considered themselves solely as Sami and those who considered themselves as Sami in addition to other ethnic groups. This allowed us to create two Sami groups that had different dietary habits ${ }^{(39)}$. We also tested an ethnicity variable that was previously used to analyse data from the SAMINOR 1 Survey ${ }^{(40)}$. In the present study, Sami ethnicity was determined based on both subjective (Sami self-perception) and objective (Sami language connection and Sami ethnic background) criteria. This variable was not selected as a predictor for vitamin D status in the final linear regression models; thus results from regression models did not differ (data not shown).

Different laboratory methods to assess $25(\mathrm{OH}) \mathrm{D}$ concentration have been used in population-based surveys and have led to substantial variability ${ }^{(8)}$, with original results often deviating considerably from standardized results $^{(15,17)}$. We used automated chemiluminescent immunoassay IDS-iSYS 25-Hydroxy Vitamin $\mathrm{D}^{\mathrm{S}}$ to assess 
S-25(OH)D concentrations. This method has been validated and certified by the VDSP. However, automated chemiluminescent immunoassays tend to overestimate circulating $25(\mathrm{OH}) \mathrm{D}$ concentrations ${ }^{(41)}$.

In our study, age was positively associated with S-25(OH)D concentration and this association was consistent across all the ethnic groups (Supplemental Table S1). These associations have been previously reported in middle-aged (44-59 years) Norwegian females living at $65-71^{\circ} \mathrm{N}^{(4)}$. However, age was not correlated with $25(\mathrm{OH}) \mathrm{D}$ concentration in a study of younger (19-55 years old) Norwegian males and females from Nord-Trøndelag (the HUNT Study) living at $64^{\circ} \mathrm{N}$ with a higher prevalence of hypovitaminosis D ( $40 \%$ had concentration $<50 \mathrm{nmol} / \mathrm{l}$ on average during four seasons, with greater prevalence in winter $60 \%$ than in summer $20 \%)^{(13)}$. In the paper from mid-Norway, daily vitamin D intake was not measured ${ }^{(13)}$. One explanation for the higher S-25(OH)D in older adults in our study is the more frequent consumption of supplements on a daily basis and a higher total daily vitamin D intake (data not shown). In fact, higher frequency of codliver oil/fish oil supplement use was strongly associated with satisfactory vitamin D status. Older individuals may eat more traditional foods, such as oily fish and cod liver, during winter. In the present study, the mean S-25(OH)D concentration was $\geq 50 \mathrm{nmol} / \mathrm{l}$ in the winter months (November, January-April) in males and females ( $62 \mathrm{nmol} / \mathrm{l})$. It is important to note that our study was performed in the rural part of northern Norway. A previous study showed that $25(\mathrm{OH}) \mathrm{D}$ concentrations in a rural coastal settlement of northern Norway in March were high (mean $67.2 \mathrm{nmol} / \mathrm{l}$, $15 \cdot 4 \%$ individuals had a concentration $<50 \mathrm{nmol} / \mathrm{l})^{(5)}$, and this was explained by high consumption of cod liver and fresh cod-liver oil during extended Arctic winter among this population.

In the present study, dietary vitamin D intake was adequate. Overall, median dietary vitamin $\mathrm{D}$ intake was $11 \mu \mathrm{g} / \mathrm{d}$ in Sami and non-Sami males, $13 \mu \mathrm{g} / \mathrm{d}$ in multiethnic Sami males and $9 \mu \mathrm{g} / \mathrm{d}$ in Sami, multi-ethnic Sami and non-Sami females. Indeed, studies from Norway that measure both vitamin D intake and $25(\mathrm{OH}) \mathrm{D}$ concentration are scarce. In the present study, dietary vitamin D intake, including intake from food and liquid cod-liver oil, was one of the strongest contributors to satisfactory vitamin D status. This finding is consistent with a previous study on predictors of satisfactory vitamin D status among Norwegian women $^{(4)}$. In our study, the median of total intake of vitamin D was $11.6 \mu \mathrm{g} / \mathrm{d}$ in males and $9.2 \mu \mathrm{g} / \mathrm{d}$ in females. Daily vitamin D intake was in line with data from a recent national nutritional survey in Norway (Norkost 3) ${ }^{(42)}$, which reported that mean dietary intake of vitamin D increased from 7 to $12 \mu \mathrm{g} / \mathrm{d}$ in males, and from 5 to $10 \mu \mathrm{g} / \mathrm{d}$ in females, when supplements were included in the calculation. Recently in the Nordic countries, authorities have recommended an increase in vitamin $\mathrm{D}$ intake, from $7.5 \mu \mathrm{g}(300 \mathrm{IU})$ to $10 \mu \mathrm{g}$ ( $400 \mathrm{IU}$ ) per day for adults. However, for individuals aged 75 years or older and for those with no or little sun exposure, $20 \mu \mathrm{g} / \mathrm{d}(800 \mathrm{IU} / \mathrm{d})$ is recommended $^{(43)}$. In Norway, some types of milk (0.4-0.8 $\mu \mathrm{g}$ vitamin D per $100 \mathrm{~g}$ ) and all margarine, butter and butter mixed with oil $(8 \mu \mathrm{g}$ vitamin D per $100 \mathrm{~g})$ are enriched with vitamin $\mathrm{D}^{(44,45)}$.

In our study, smoking and BMI were each inversely associated with S-25(OH)D, and BMI had somewhat greater impact on $25(\mathrm{OH})$ concentration. A recent systematic review on the non-skeletal health effects of vitamin D supplementation concluded that it is generally agreed that obesity results in low $25(\mathrm{OH}) \mathrm{D}$. However, vitamin D supplementation was not associated with weight loss in randomized clinical trials ${ }^{(46)}$. The negative association between smoking status (never $v$. current) and $25(\mathrm{OH}) \mathrm{D}$ has been consistently described in observational studies ${ }^{(47-50)}$. A Danish study found that, in addition to reduced concentration of $25(\mathrm{OH}) \mathrm{D}$, smokers had reduced concentrations of the biologically active form of vitamin D, 1,25-dihydroxyvitamin D, and parathyroid hormone. The study hypothesized that the depression of the vitamin D-parathyroid hormone system seen among smokers is likely to be involved in these associations $^{(51)}$.

In females, higher alcohol intake (non-consumers $v$. $\geq 6 \mathrm{~g}$ alcohol/d) was associated with higher S-25(OH)D. Females reported significantly less alcohol consumption and there were more non-consumers of alcohol among females than males. The association between alcohol consumption and vitamin D concentrations has been previously reported ${ }^{(13,52,53)}$. It has been speculated that alcohol can suppress the conversion of $25(\mathrm{OH}) \mathrm{D}$ to $1,25-$ dihydroxyvitamin $\mathrm{D}^{(54)}$ and, due to that, higher $25(\mathrm{OH}) \mathrm{D}$ concentrations might be associated with higher alcohol consumption.

UVB-induced vitamin D production is absent/limited for a considerable part of the year in northern Norway. The number of self-reported daylight hours outside in the week prior to blood sampling was a positive predictor of $\mathrm{S}-25(\mathrm{OH}) \mathrm{D}$ concentration in univariable regression models in males and females. However, this association was not significant in multivariable regression models. In fact, the predictive power of having been on a sunbathing holiday in the past month was much stronger.

The present study has limitations. The response rate was low (47\%) and the generalizability of our results due to selection bias can be questioned. In addition, the sample was limited to individuals aged 40-69 years and cannot be generalized to younger or older individuals. Only ten municipalities were included in the study and geographic comparisons are difficult, as different municipalities were measured at different times of the year. We studied both males and females, but the response was higher among females. Another relevant limitation is that the FFQ has not been specifically validated in males or in the Indigenous Sami population. In addition, we used self- 
reported data on dietary intake and lifestyle factors, thus we cannot exclude some recall bias. Moreover, it is difficult to accurately measure UVB exposure in large population studies, and we did not have information on protective sun behaviour which could affect vitamin D status. Our study was not designed to investigate the influence of genetic polymorphisms; however, genetic factors have recently been considered to contribute greatly to vitamin D status ${ }^{(47,55-57)}$

The strength of the present study is the large sample size. Only a few large studies have been designed to simultaneously explore the impact of dietary intakes, supplements, some important factors that related to UVB exposure, and a broad range of lifestyle and sociodemographic factors that are known to influence circulating $25(\mathrm{OH}) \mathrm{D}$ concentration. In the present study, trained local medical staff examined participants according to a standard protocol. We used a validated, comprehensive FFQ to estimate total dietary vitamin $\mathrm{D}^{(30,31)}$, and BMI was calculated based on anthropometric measurements, which are more accurate than self-reported data. We excluded non-Western migrants as they might have inferior $25(\mathrm{OH}) \mathrm{D}$ status due to different nutritional and cultural habits ${ }^{(58)}$.

\section{Conclusion}

In conclusion, our data provide important information for both public health authorities and clinicians. Overall, a quarter of middle-aged residents of rural northern Norway had insufficient vitamin D status on average in the year, although the sunniest summer months were not included. The prevalence of vitamin D deficiency and insufficiency we found was not as high as that in some European and Arctic Indigenous populations, with very few individuals having S-25(OH)D concentration $<30 \mathrm{nmol} / \mathrm{l}$. It appears that the Indigenous Sami group has sufficient S-25(OH)D concentrations. Total dietary vitamin $\mathrm{D}$ intake was one of the main contributors to higher S-25(OH)D concentration in this multi-ethnic population. In addition, travelling to southern countries for sunbathing vacations can increase these concentrations substantially. Adequate dietary intake of vitamin $\mathrm{D}$ is necessary to prevent hypovitaminosis D in this geographical area. Daily intake of vitamin D supplements, preferably cod-liver oil at least during the dark periods (autumn and winter months), as well as a diet rich in vitamin $\mathrm{D}$, seems to be a good prophylactic measure against hypovitaminosis $\mathrm{D}$.

\section{Acknowledgements}

Acknowledgements: The authors would like to gratefully acknowledge the participants and staff of the SAMINOR 2 Clinical Survey, and the Centre for Sami Health
Research, UiT The Arctic University of Norway, for access to the data. Financial support: The SAMINOR 2 Clinical Survey was financed by the Norwegian Ministry of Health and Care Services; the Northern Norway Regional Health Authority; the Regional Research Fund of Northern Norway; the Sami Parliament; the Sami Norwegian National Advisory Unit on Mental Health and Substance Use; and the Finnmark, Troms and Nordland County councils. The present postdoctoral research project was financially supported by Department of Community Medicine, UiT The Arctic University of Norway. The funders had no role in the design, analysis or writing of this article. Conflict of interest: N.P., C.L.-A., M.M., A.R.B. and M.B. have no conflicts of interest or financial ties to disclose. Authorship: N.P. analysed the data and wrote manuscript. C.L.-A. was responsible for $\mathrm{S}-25(\mathrm{OH}) \mathrm{D}$ measurements and critically revised the paper. M.M. was responsible for the database, helped with the statistical analysis, designed the map of the study and critically revised the paper. A.R.B., research leader of the SAMINOR 2 Clinical Survey, contributed to conception and design and revised the paper. M.B., leader of the present research project, designed the study and critically revised the paper. All authors contributed to the interpretation of data and approved the final version of manuscript. Ethics of buman subject participation: The Regional Committee for Medical and Health Research Ethics of Northern Norway (REC North) approved the SAMINOR 2 Clinical Survey. The storing of personal data for the SAMINOR 2 Clinical Survey was approved by the National Data Inspectorate. The application for this research project was approved by the Regional Committee for Medical and Health Research Ethics of Northern Norway (REC North). All participants signed an informed consent form.

\section{Supplementary material}

To view supplementary material for this article, please visit https://doi.org/10.1017/\$1368980018003816

\section{References}

1. Lamberg-Allardt C, Brustad M, Meyer HE et al. (2013) Vitamin D - a systematic literature review for the 5th edition of the Nordic Nutrition Recommendations. Food Nutr Res 2013, 57.

2. Lips P (2006) Vitamin D physiology. Prog Biophys Mol Biol 92, 4-8.

3. Lamberg-Allardt C (2006) Vitamin D in foods and as supplements. Prog Biophys Mol Biol 92, 33-38.

4. Brustad M, Alsaker E, Engelsen O et al. (2004) Vitamin D status of middle-aged women at 65-71 degrees $\mathrm{N}$ in relation to dietary intake and exposure to ultraviolet radiation. Public Health Nutr 7, 327-335.

5. Brustad M, Sandanger T, Aksnes L et al. (2004) Vitamin D status in a rural population of northern Norway with high fish liver consumption. Public Health Nutr 7, 783-789. 
6. Cashman KD \& Kiely M (2011) Nutrition: new guidelines on vitamin D-ficiency - clear or confusing? Nat Rev Endocrinol 7, 566-568.

7. Institute of Medicine (2011) Dietary Reference Intakes for Calcium and Vitamin D. Washington, DC: National Academies Press.

8. Cashman KD, Dowling KG, Skrabakova Z et al. (2016) Vitamin D deficiency in Europe: pandemic? Am J Clin Nutr 103, 1033-1044.

9. Oberg J, Jorde R, Almas B et al. (2014) Vitamin D deficiency and lifestyle risk factors in a Norwegian adolescent population. Scand J Public Health 42, 593-602.

10. Kjaergaard M, Joakimsen R \& Jorde R (2011) Low serum 25hydroxyvitamin D levels are associated with depression in an adult Norwegian population. Psychiatry Res 190 , 221-225.

11. Jorde R, Sneve M, Hutchinson M et al. (2010) Tracking of serum 25-hydroxyvitamin D levels during 14 years in a population-based study and during 12 months in an intervention study. Am J Epidemiol 171, 903-908.

12. Meyer HE, Falch JA, Sogaard AJ et al. (2004) Vitamin D deficiency and secondary hyperparathyroidism and the association with bone mineral density in persons with Pakistani and Norwegian background living in Oslo, Norway, The Oslo Health Study. Bone 35, 412-417.

13. Larose TL, Chen Y, Camargo CA Jr et al. (2014) Factors associated with vitamin D deficiency in a Norwegian population: the HUNT Study. I Epidemiol Community Health 68, 165-170.

14. Holvik K, Ahmed LA, Forsmo S et al. (2013) Low serum levels of 25-hydroxyvitamin D predict hip fracture in the elderly: a NOREPOS study. J Clin Endocrinol Metab 98, 3341-3350.

15. Cashman KD, Kiely M, Kinsella M et al. (2013) Evaluation of Vitamin D Standardization Program protocols for standardizing serum 25-hydroxyvitamin D data: a case study of the program's potential for national nutrition and health surveys. Am J Clin Nutr 97, 1235-1242.

16. Durazo-Arvizu RA, Tian L, Brooks SPJ et al. (2017) The Vitamin D Standardization Program (VDSP) manual for retrospective laboratory standardization of serum 25-hydroxyvitamin D data. J AOAC Int 100, 1234-1243.

17. Cashman KD, Dowling KG, Skrabakova Z et al. (2015) Standardizing serum 25-hydroxyvitamin D data from four Nordic population samples using the Vitamin D Standardization Program protocols: shedding new light on vitamin D status in Nordic individuals. Scand J Clin Lab Invest $\mathbf{7 5}$, 549-561.

18. Brustad M, Braaten T \& Lund E (2004) Predictors for codliver oil supplement use - the Norwegian Women and Cancer Study. Eur J Clin Nutr 58, 128-136.

19. O'Neill CM, Kazantzidis A, Ryan MJ et al. (2016) Seasonal changes in vitamin D-effective UVB availability in Europe and associations with population serum 25-hydroxyvitamin D. Nutrients 8, E533.

20. Sem SW, Sjoen RJ, Trygg K et al. (1987) Vitamin D status of two groups of elderly in Oslo: living in old people's homes and living in own homes. Compr Gerontol $A \mathbf{1}$, 126-130.

21. Madar AA, Stene LC \& Meyer HE (2009) Vitamin D status among immigrant mothers from Pakistan, Turkey and Somalia and their infants attending child health clinics in Norway. Br J Nutr 101, 1052-1058.

22. Holvik K, Meyer HE, Haug E et al. (2005) Prevalence and predictors of vitamin D deficiency in five immigrant groups living in Oslo, Norway: the Oslo Immigrant Health Study. Eur J Clin Nutr 59, 57-63.

23. Christensen MH, Lien EA, Hustad S et al. (2010) Seasonal and age-related differences in serum 25-hydroxyvitamin D, 1,25-dihydroxyvitamin $\mathrm{D}$ and parathyroid hormone in patients from Western Norway. Scand J Clin Lab Invest $\mathbf{7 0}$, 281-286

24. Engelsen O, Brustad M, Aksnes L et al. (2005) Daily duration of vitamin D synthesis in human skin with relation to latitude, total ozone, altitude, ground cover, aerosols and cloud thickness. Photochem Photobiol 81, 1287-1290.

25. El Hayek Fares J \& Weiler HA (2016) Implications of the nutrition transition for vitamin $\mathrm{D}$ intake and status in Aboriginal groups in the Canadian Arctic. Nutr Rev $\mathbf{7 4}$, 571-583.

26. Andersen S, Laurberg P, Hvingel B et al. (2013) Vitamin D status in Greenland is influenced by diet and ethnicity: a population-based survey in an Arctic society in transition. $\mathrm{Br}$ J Nutr 109, 928-935.

27. Kloster J (1931) The distribution and frequency of rickets in one of the fishery districts of Finmark and relation of diet to the disorder. Acta Paediatr 12, issue S3, 3-82.

28. Brustad M, Parr CL, Melhus M et al. (2008) Dietary patterns in the population living in the Sami core areas of Norway the SAMINOR study. Int J Circumpolar Health 67, 82-96.

29. Lund E, Dumeaux V, Braaten T et al. (2008) Cohort profile: The Norwegian Women and Cancer Study - NOWAC Kvinner og kreft. Int J Epidemiol 37, 36-41.

30. Hjartaker A, Andersen LF \& Lund E (2007) Comparison of diet measures from a food-frequency questionnaire with measures from repeated 24-hour dietary recalls. The Norwegian Women and Cancer Study. Public Health Nutr 10, 1094-1103.

31. Hjartaker A, Lund E \& Bjerve KS (1997) Serum phospholipid fatty acid composition and habitual intake of marine foods registered by a semi-quantitative food frequency questionnaire. Eur J Clin Nutr 51, 736-742.

32. Holick MF, Binkley NC, Bischoff-Ferrari HA et al. (2011) Evaluation, treatment, and prevention of vitamin D deficiency: an Endocrine Society clinical practice guideline. $J$ Clin Endocrinol Metab 96, 1911-1930.

33. Commission of the European Communities (1993) Vitamin D. In Nutrient and Energy Intakes of the European Community. Report of the Scientific Committee of Food (31st Series), pp. 132-139. Luxembourg: Office for Official Publications of the European Communities.

34. Ramnemark A, Norberg M, Pettersson-Kymmer U et al. (2015) Adequate vitamin D levels in a Swedish population living above latitude 63 degrees $\mathrm{N}$ : the 2009 Northern Sweden MONICA study. Int J Circumpolar Health $\mathbf{7 4 ,}$ 27963.

35. Jablonski NG \& Chaplin G (2012) Human skin pigmentation, migration and disease susceptibility. Philos Trans $R$ SOC Lond B Biol Sci 367, 785-792.

36. Rabenberg M, Scheidt-Nave C, Busch MA et al. (2015) Vitamin D status among adults in Germany - results from the German Health Interview and Examination Survey for Adults (DEGS1). BMC Public Health 15, 641.

37. Sharma S, Barr AB, Macdonald HM et al. (2011) Vitamin D deficiency and disease risk among aboriginal Arctic populations. Nutr Rev 69, 468-478.

38. Nielsen NO, Jorgensen ME, Friis H et al. (2014) Decrease in vitamin D status in the Greenlandic adult population from 1987-2010. PLoS One 9, e112949.

39. Petrenya N, Skeie G, Melhus M et al. (2018) Food in rural northern Norway in relation to Sami ethnicity: the SAMINOR 2 Clinical Survey. Public Health Nutr 21, 2665-2677.

40. Naseribafrouei A, Eliassen BM, Melhus M et al. (2016) Ethnic difference in the prevalence of pre-diabetes and diabetes mellitus in regions with Sami and non-Sami populations in Norway - the SAMINOR1 study. Int I Circumpolar Health 75, 31697.

41. Hollis BW (2008) Measuring 25-hydroxyvitamin D in a clinical environment: challenges and needs. Am J Clin Nutr $\mathbf{8 8}$, issue 2 , 507S-510S. 
42. Totland TH, Helsedirektoratet (2012) Norkost 3: en landsomfattende kostholdsundersøkelse blant menn og kvinner $i$ Norge $i$ alderen 18-70 år, 2010-2011. Oslo: Helsedirektoratet.

43. Nordic Council of Ministers (2012) Nordic Nutrition Recommendations 2012: Integrating Nutrition and Physical Activity, 5th ed. Copenhagen: Nordic Council of Ministers.

44. Spiro A \& Buttriss JL (2014) Vitamin D: an overview of vitamin D status and intake in Europe. Nutr Bull 39, 322-350.

45. Matportalen.no (2018) About the food groups. http:// www.matportalen.no/verktoy/the_norwegian_food_compo sition_table/about_the_food_groups (accessed September 2018).

46. Rejnmark L, Bislev LS, Cashman KD et al. (2017) Non-skeletal health effects of vitamin D supplementation: a systematic review on findings from meta-analyses summarizing trial data. PLoS One 12, e0180512.

47. Kuhn T, Kaaks R, Teucher B et al. (2014) Dietary, lifestyle, and genetic determinants of vitamin D status: a crosssectional analysis from the European Prospective Investigation into Cancer and Nutrition (EPIC)-Germany study. Eur J Nutr 53, 731-741.

48. Thuesen B, Husemoen L, Fenger M et al. (2012) Determinants of vitamin D status in a general population of Danish adults. Bone 50, 605-610.

49. Lamberg-Allardt CJ, Outila TA, Karkkainen MU et al. (2001) Vitamin D deficiency and bone health in healthy adults in Finland: could this be a concern in other parts of Europe? J Bone Miner Res 16, 2066-2073.
50. Tonnesen R, Hovind PH, Jensen LT et al. (2016) Determinants of vitamin $\mathrm{D}$ status in young adults: influence of lifestyle, sociodemographic and anthropometric factors. BMC Public Health 16, 385.

51. Brot C, Jorgensen NR \& Sorensen OH (1999) The influence of smoking on vitamin D status and calcium metabolism. Eur J Clin Nutr 53, 920-926.

52. Lee K (2012) Sex-specific relationships between alcohol consumption and vitamin D levels: the Korea National Health and Nutrition Examination Survey 2009. Nutr Res Pract 6, 86-90.

53. Skaaby T, Husemoen LL, Thuesen BH et al. (2016) Longitudinal associations between lifestyle and vitamin D: a general population study with repeated vitamin $\mathrm{D}$ measurements. Endocrine 51, 342-350.

54. Turner RT, Aloia RC, Segel LD et al. (1988) Chronic alcohol treatment results in disturbed vitamin D metabolism and skeletal abnormalities in rats. Alcohol Clin Exp Res 12, 159-162.

55. Bouillon R (2010) Genetic and environmental determinants of vitamin D status. Lancet 376, 148-149.

56. Wang TJ, Zhang F, Richards JB et al. (2010) Common genetic determinants of vitamin $\mathrm{D}$ insufficiency: a genomewide association study. Lancet 376, 180-188.

57. Touvier M, Deschasaux M, Montourcy M et al. (2015) Determinants of vitamin D status in Caucasian adults: influence of sun exposure, dietary intake, sociodemographic, lifestyle, anthropometric, and genetic factors. J Invest Dermatol 135, 378-388.

58. Mithal A, Wahl DA, Bonjour JP et al. (2009) Global vitamin D status and determinants of hypovitaminosis D. Osteoporosis Int 20, 1807-1820. 